\title{
Benefits that could be achieved by a proper reactive power generation in small photovoltaic systems operating inside low voltage distribution network
}

\author{
Katarina Dežan, Ernest Belič and Gorazd Štumberger \\ University of Maribor \\ Faculty of Electrical Engineering and Computer Science \\ Smetanova ulica 17, 2000 Maribor, Slovenia \\ e-mail: katarina.dezan@um.si, ernest.belic@um.si, gorazd.stumberger@um.si
}

\begin{abstract}
The reduction of feed-in tariffs and subsidies in the last years substantially decreased the interest of investors for photovoltaic (PV) systems in individual countries and in the European Union in general. From the viewpoint of electricity distribution system operators (DSO) and electricity distribution companies, the PV systems are often observed as the systems that cause additional costs and make network operation difficult, but must be connected to the electricity network due to the existing legislation. Thus, the power of PV systems newly connected to the electricity networks per year decreases substantially. The fact that PV systems can be used not only for active, but also for reactive power generation, is often neglected. If reactive power in PV systems is generated properly, it can satisfy the local reactive power demand, which leads to reduction of network losses. This paper focuses on an existing low voltage distribution network with installed $100 \mathrm{kWp} \mathrm{PV}$ power. Its goal is to perform a sensitivity analysis of benefits in the network that could be achieved by the reduction of network energy losses and by the locally generated reactive power, both achieved by PV systems capable to generate reactive power.
\end{abstract}

\section{Key words}

Distribution network, photovoltaic system, reactive power generation, savings, economic analysis, sensitivity analysis.

\section{Introduction}

Electrical energy generated by power plants passes through the electricity transmission and distribution networks before it finally reaches the consumers. In this process appear transmission and distribution system losses, which represent the difference between the generated and delivered energy. These energy losses are mostly caused by the unidirectional energy flow known as the active power as well as by the reciprocal energy exchange known as the reactive power. According to the official statistical data [1] for 2013, the total energy losses in Slovenian electricity transmission and distribution networks are in the range of $849 \mathrm{GWh}$, as shown in Table I. This is $5,7 \%$ of transmitted energy, including transit, export and import of electrical energy. However, it must be pointed out that costs for the operation of transmission and distribution networks could be even more important than the energy losses.

Table I. - Electricity consumption and losses in year 2013

\begin{tabular}{|l|r|}
\hline Total consumption $(\mathrm{GWh})$ & 12.816 \\
\hline Transmission losses $(\mathrm{GWh})$ & 307 \\
\hline Distribution losses $(\mathrm{GWh})$ & 542 \\
\hline Total network losses $(\mathrm{GWh})$ & 849 \\
\hline
\end{tabular}

This paper focuses on the benefits that can be achieved by a proper generation of reactive power in PV systems installed inside a low voltage distribution network [2]-[5]. In the case study, given for an existing low voltage network, the savings due to the reduced energy losses and costs related with it, as well as the benefits due to the locally provided reactive power, are analysed. Performed are the evaluations based on the discounted cash flow $(D C F)$ analysis and the sensitivity analysis.

\section{Low voltage network and legal frame}

The analysis performed in this paper focuses on the low voltage distribution network shown in Fig. 1. It contains a transformer $250 \mathrm{kVA}$, Dy5n, $20 \mathrm{kV} / 0.4 \mathrm{kV}, 35$ consumers with total maximum active power of $130 \mathrm{~kW}$, and two $50 \mathrm{kWp} \mathrm{PV}$ systems. The total energy consumption is in the range of $150 \mathrm{MWh}$ and $72 \mathrm{MVArh}$. According to the rules defined by the electricity distribution system operator (DSO), all PV systems connected to the network must be able to generate reactive power according to $\cos \varphi=0.8$, whilst $\cos \varphi$ of the consumers must be better than 0.9 .

The first aim of this work is to evaluate the benefits that can be achieved in the discussed low voltage network by the reduction of energy losses due to optimal reactive power generation in the PV systems. The PV systems are considered in two different ways, as two actually installed $50 \mathrm{kWp}$ units, and as 20 smaller $5 \mathrm{kWp}$ units distributed 
in the network. The evaluation is based on the net present value calculation.

The second aim is to evaluate the benefits that can be achieved through the reduction of costs for reactive power. The reactive power, normally delivered from the medium voltage network or from the compensation devices, is in the given case generated locally in the PV systems, which reduces the reactive power costs. In order to evaluate the benefits achieved in this way the sensitivity analysis is performed.

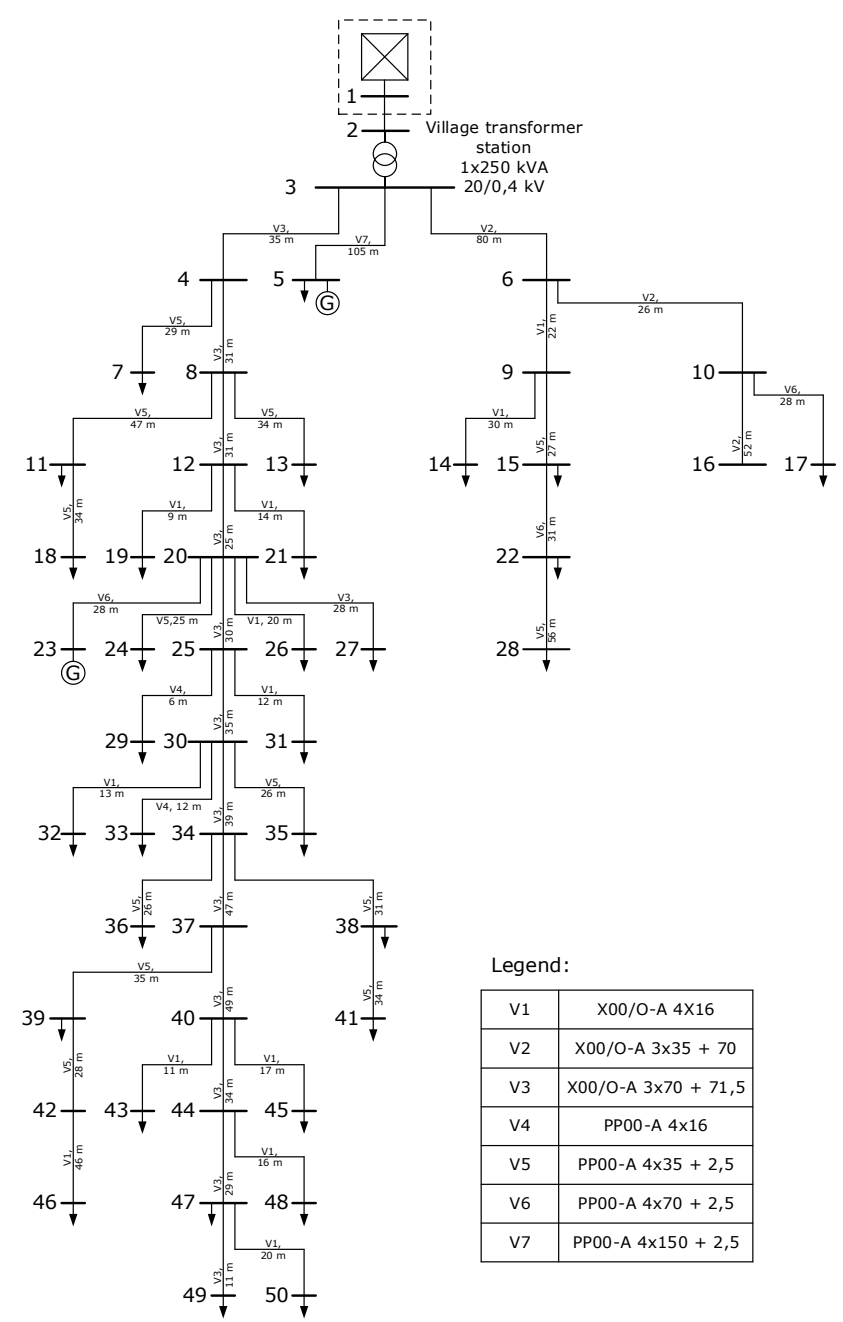

Figure 1: Discussed low voltage network with installed PV systems

\section{Benefits due to the reduction of network losses}

The network analysis is based on the load flow [6-8] analysis considering the load diagram and solar irradiance data given in 30 min intervals over a year. For each 30 min interval, the optimal reactive power generation is determined in such a way, to minimize the energy losses related with energy transmission in the networks and to simultaneously keep the voltage profile inside prescribed limits. In order to generated references for reactive power generation in individual PV systems a local low voltage network control based on instantaneous smart meter data can be applied. The reduction of losses is then represented in the form of cost savings. The described procedure is performed for two $50 \mathrm{kWp} \mathrm{PV} \mathrm{systems} \mathrm{that} \mathrm{are} \mathrm{actually}$ installed in network, where they are marked with $\mathrm{G}$ in Fig. 1, and for 20 hypothetical smaller PV systems. The benefits in the form of cost savings $C_{\text {savings }}[€]$, that could be achieved through the reduction of network losses related with energy transmission $W_{\text {loss }}$ [MWh], are calculated by (1) as the product of the energy savings and the cost of energy losses $C_{\text {loss }}$ [ $\left.€ / \mathrm{MWh}\right]$.

$$
C_{\text {savings }}=W_{\text {loss }} \times C_{\text {loss }}
$$

The results presented in Table II. are given for the energy saving per year, considering officially defined cost of energy losses $C_{\text {loss }}=51.00 € / \mathrm{MWh}$, valid nationally in 2014. The energy savings are calculated for the discussed network as the difference between the network energy losses in in the case without reactive power generation and the case with optimal reactive power generation in the PV systems. The PV systems are considered in two different ways, by two $50 \mathrm{kWp}$ units and by 10 units with the power of $5 \mathrm{kWp}$.

Table II. - Energy and cost savings per year

\begin{tabular}{|l|c|c|c|}
\hline $\begin{array}{r}\text { Type of } \\
\text { Network }\end{array}$ & $\begin{array}{c}\text { Savings } \\
\text { per year }\end{array}$ & $\begin{array}{c}\text { Actual PV } \\
\text { systems } \\
2 \times 50 \mathrm{kWp}\end{array}$ & $\begin{array}{l}\text { Small PV } \\
\text { systems } \\
20 \times 5 \mathrm{kWp}\end{array}$ \\
\hline $\begin{array}{l}\text { Village } \\
\text { network }\end{array}$ & $W_{\text {loss }}[\mathrm{MWh}]$ & 1.148 & 1.698 \\
\cline { 2 - 4 } & $C_{\text {savings }}[€]$ & 58.528 & 86.578 \\
\hline
\end{tabular}

In the results presented in Table II. only cost savings due to the reduced network losses are considered, whilst the costs for reactive power are not considered. In the low voltage networks, the reactive power is normally generated with compensation devices or it must be delivered form the reactive power sources in the medium voltage network. In any case the reactive power must be provided for proper network operation and it cannot be considered as granted and costs free.

\section{Benefits due to the local reactive power generation}

In the given case, the reactive power demand and resources for its generation are well defined due to the known network model, load profile and profile of PV system operation. However, they can be also estimated.

According to the DSO rules, all PV systems connected to the network must generate reactive power according to $\cos \varphi=0.8$, whilst $\cos \varphi$ of the consumers must be better than 0.9 . Considering the relation between the active $P$ and reactive power $Q(2)$

$\cos \varphi=\frac{P}{\sqrt{P^{2}+Q^{2}}} \Rightarrow Q=P \sqrt{\frac{1}{\cos ^{2} \varphi}-1}$

and taking into account that $\cos \varphi=0.8$ for reactive power generation and $\cos \varphi=0.9$ for reactive power demand, the 
relations $Q=0.75 P$ for the reactive power generation and $Q=0.48 P$ for the reactive power demand, can be used as a first approximation. The average yearly energy consumption per consumer in the discussed network is $4286 \mathrm{kWh}$, which gives the total consumption of approximately $150 \mathrm{MWh}$ and $72 \mathrm{MVArh}$ per year. With 1100 hours of operation at the installed power, the two PV systems in the network can generate approximately 110 MWh and 82.5 MVArh per year. Thus, the reactive power demand of the consumers as well as reactive power required for low voltage network operation could be provided locally, which is not completely true because the PV systems cannot operate without sunlight.

The benefits in the form of power system cost savings due to the locally generated reactive power per year can be calculated by (3):

$$
P S_{\text {savings }}=V A r_{\text {gen }} \times C_{\text {gen }}
$$

where are:

$P S_{\text {savings }}$-the power system cost savings in [€],

$V A r_{g e n^{-}}$the reactive power generated locally [MVArh], $C_{g e n}$ - the cost for the generated reactive power [€/MVArh].

Table III. gives the calculated values of savings in EUR per year, considering the reactive power generation of 72 MVArh. The value of the parameter $C_{g e n}$, that represents the cost of reactive power and is defined in (3), is assumed to $b e=25.50$ [ $€ / \mathrm{MVArh}$, which is half of the price of energy losses. The sensitivity analysis will be performed in the section 6 .

Table III. - Power system savings per year

\begin{tabular}{|l|c|c|c|}
\hline $\begin{array}{c}\text { Type of } \\
\text { Network }\end{array}$ & $\begin{array}{c}\text { Savings } \\
\text { per year }\end{array}$ & $\begin{array}{c}\text { Actual PV } \\
\text { systems } \\
2 \times 50 \mathrm{kWp}\end{array}$ & $\begin{array}{c}\text { Small PV } \\
\text { systems } \\
20 \times 5 \mathrm{kWp}\end{array}$ \\
\hline $\begin{array}{l}\text { Village } \\
\text { network }\end{array}$ & $P S_{\text {savings }}[€]$ & 1836.00 & 1836.00 \\
\hline
\end{tabular}

\section{Discounted cash flow analysis}

The benefits discussed in the sections 3 and 4, presented in Tables II and III, are evaluated together using the discounted cash flow (DCF) analysis. The DCF analysis performed in this work is based on the Net Present Value $N P V$ of investment (4):

$$
N P V=\sum_{t=0}^{N} \frac{C F_{t}}{(1+r)^{t}}-I
$$

where are:

$I$ - the initial investment cost in [€],

$C F$ - the cash flow (inflows minus outflows) in the year $t$,

$N$ - the life span of the project in years,

$r$ - the investment required rate of return.
In the analysis it is considered that the time of the cash flow is 20 years and the required investment rate of return is $7 \%$. The yearly cash flow $C F$ (5) consists of the cash outflows, which, in the given case, equals zero and the yearly cash inflows, which represent the benefits $C_{\text {savings }}$ and $P S_{\text {savings }}$, introduced in (1) and (3), respectively.

$$
C F=\left(C_{\text {savings }}+P S_{\text {savings }}\right)-\text { outflows }
$$

The NPV represent the difference between sum of the investment discounted cash flows and its cost essentially. $N P V$ measures how much value is created or added by undertaking an investment. In the given case, the initial investment cost $I$ in (4) equals zero, whilst the cash flow $C F$ in (5) consist only of benefits $C_{\text {savings }}$ and $P S_{\text {savings }}$.

The results of $N P V$ determined for two different scenarios

\begin{tabular}{|c|c|c|c|}
\hline $\begin{array}{l}\text { Type of } \\
\text { Network }\end{array}$ & $N P V$ & $\begin{array}{c}\text { Actual PV } \\
\text { systems } \\
2 \times 50 \mathrm{kWp}\end{array}$ & $\begin{array}{l}\text { Small PV } \\
\text { systems } \\
20 \times 5 \mathrm{kWp}\end{array}$ \\
\hline \multirow{2}{*}{$\begin{array}{l}\text { Village } \\
\text { network }\end{array}$} & Scenario A & $620.04 €$ & $917.20 €$ \\
\hline & Scenario B & $20070.65 €$ & $20367.81 €$ \\
\hline
\end{tabular}
are shown in Table IV and in figures 2 and 3.

Table IV. NPV of 20 -year investment with $7 \%$ profitability index

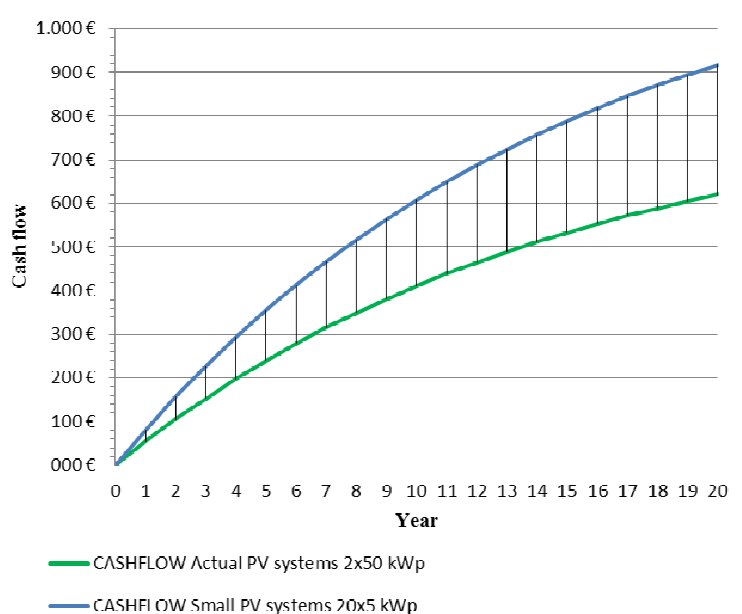

Figure 2: $N P V$ for the Scenario A

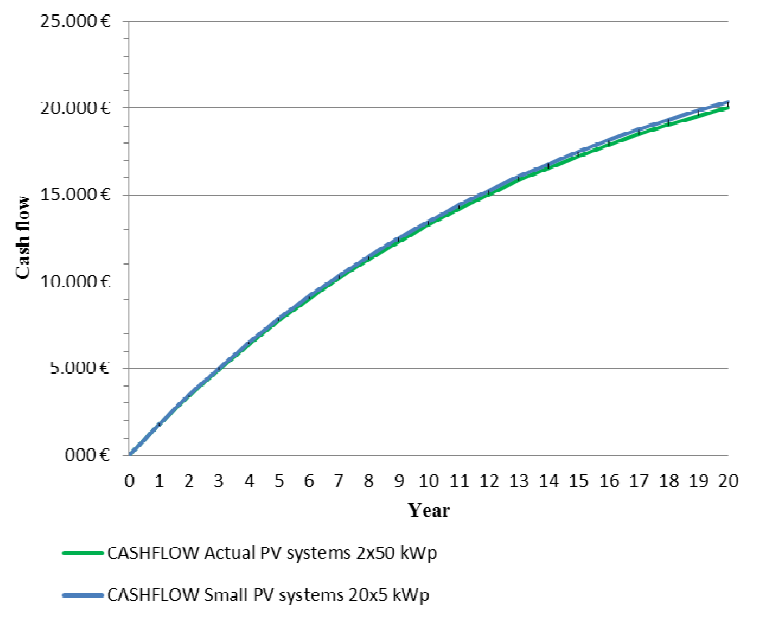

Figure 3: $N P V$ for the Scenario B 
In the Scenario A only the benefits achieved by the cost savings due to reduction of losses $\left(\mathrm{C}_{\text {savings }}\right)$ are considered. However, in the Scenario B both, the benefits achieved by the cost savings due to reduction of losses $\left(C_{\text {savings }}\right)$, as well as the benefits achieved by the cost savings due to the locally generated reactive power $\left(P S_{\text {savings }}\right)$, are considered. The results are given for the discussed low voltage network with the total PV power of $100 \mathrm{kWp}$. The PV systems are considered in two ways, as two $50 \mathrm{kWp}$ $\mathrm{PV}$ units and as twenty $5 \mathrm{kWp} \mathrm{PV}$ units.

\section{Sensitivity analysis}

The results shown in Table IV and in figures 2 and 3 are given for the cost of energy losses $C_{\text {loss }}=51.00 € / \mathrm{MWh}$ and the cost for generated reactive power $C_{\text {gen }}=25.5$ $€ / M V A r h$. However, these costs are not fixed and can change in the similar way as the energy prices on the market.

Table V. The impact of costs $C_{\text {loss }}$ and $C_{\text {gen }}$ on yearly benefits in the network with two $50 \mathrm{kWp}$ PV units

\begin{tabular}{|c|c|c|c|c|c|c|}
\hline \multirow{3}{*}{\multicolumn{2}{|c|}{$\begin{array}{l}\text { Yearly Savings } \\
\text { Actual PV systems } \\
2 \times 50 \mathrm{kWp}\end{array}$}} & \multicolumn{5}{|c|}{ Cost of enery losses [€/MWh] } \\
\hline & & $-40 \%$ & $-20 \%$ & 0 & $20 \%$ & $40 \%$ \\
\hline & & 30.60 & 40.80 & 51.00 & 61.20 & 71.40 \\
\hline \multirow{5}{*}{$\begin{array}{c}\text { Cost of } \\
\text { reactive } \\
\text { power } \\
\text { energy } \\
\text { [€/MVArh] }\end{array}$} & 0.00 & 35.12 & 46.82 & 58.53 & 70.23 & 81.94 \\
\hline & 2.50 & 215.12 & 226.82 & 238.53 & 250.23 & 261.94 \\
\hline & 12.75 & 953.12 & 964.82 & 976.53 & 988.23 & 999.94 \\
\hline & 25.50 & 1871.12 & 1882.82 & 1894.53 & 1906.23 & 1917.94 \\
\hline & 51.00 & 3707.12 & 3718.82 & 3730.53 & 3742.23 & 3753.94 \\
\hline
\end{tabular}

Table VI. The impact of costs $C_{\text {loss }}$ and $C_{\text {gen }}$ on yearly benefits in the network with twenty $5 \mathrm{kWp}$ PV units

\begin{tabular}{|c|c|c|c|c|c|c|}
\hline \multirow{2}{*}{$\begin{array}{c}\text { Yearly Savings Small } \\
\text { PV systems 20x5 } \\
\mathrm{kWp}\end{array}$} & \multicolumn{5}{|c|}{ Cost of enery losses [€/MWh] } \\
\cline { 2 - 7 } & $-40 \%$ & $-20 \%$ & 0 & $20 \%$ & $40 \%$ \\
\cline { 2 - 7 } & 0.00 & 51.95 & 69.26 & 86.58 & 103.89 & 121.21 \\
\cline { 2 - 7 } & 2.50 & 231.95 & 249.26 & 266.58 & 283.89 & 301.21 \\
\cline { 2 - 7 } $\begin{array}{c}\text { Cost of } \\
\text { reactive } \\
\text { power } \\
\text { energy } \\
{[€ / \text { MVArh] }}\end{array}$ & 12.75 & 969.95 & 987.26 & 1004.58 & 1021.89 & 1039.21 \\
\cline { 2 - 7 } & 25.50 & 1887.95 & 1905.26 & 1922.58 & 1939.89 & 1957.21 \\
\cline { 2 - 7 } & 51.00 & 3723.95 & 3741.26 & 3758.58 & 3775.89 & 3793.21 \\
\hline
\end{tabular}

In order to evaluate the impact of the aforementioned variation of costs on achieved benefits per year, a sensitivity analysis is performed. This means that the calculations of yearly cash flow $C F$ (5) are performed for different values of $C_{\text {loss }}$ (1) and $C_{\text {gen }}$ (3). In the results shown in Tables $\mathrm{V}$ and $\mathrm{V}$, the cost of energy losses $C_{\text {loss }}$ are increased and decreased for $20 \%$ and for $40 \%$, whilst the cost for generated reactive power $C_{g e n}$ are set to 0 , 2.50, 12.75, 25.50 and 51.00 €/MVArh.

\section{Conclusion}

According to the rules defined by the DSO, all PV systems connected to electricity networks in Slovenia, must contribute to the reactive power generation between $\cos \varphi=0.8$ and $\cos \varphi=1$. The paper shows that, in the discussed low voltage network, the installed PV systems could generate more than 82 MVArh of reactive power.

Properly generated reactive power in PV systems can reduce the energy losses for more than $1 \mathrm{MWh}$ yearly, which means benefits of over $50 €$. Moreover, these benefits are even higher if the costs for reactive power generation are considered. According to the results presented in the paper, the benefits achieved in a single low voltage network are in the range between several tenths to several thousandths EUR. Thus, the PV systems, if applied properly, can lead to substantial benefits in distribution networks even through the reactive power generation.

\section{Acknowledgement}

This work was supported in part by Slovenian Research Agency under research contract L2-5489.

\section{References}

[1] Energy Agency of the Republic of Slovenia, "Report on the Energy Sector in Slovenia for $2013 \ll$,

[2] Fangxing Li, Wenjuan Zhang, Leon M. Tolbert, John D. Kueck, and D. Tom Rizy, "Assessment of the Economic Benefits from Reactive Power Compensation," Proceeding of the IEEE Power Systems Conference and Exposition (PSCE) 2006, pp. 1767-1773.

[3] Jan von Appen, Chris Marnay, Michael Stadler, Ilan Momber, David Klapp, Alexander von Scheven, "Assessment of the economic potential of microgrids for reactive power supply", 2011 IEEE 8th International Conference on Power Electronics and ECCE Asia (ICPE ECCE); 01/2011, pp. 809-816.

[4] M. Braun, "Reactive Power Supplied by PV Inverters - CostBenefit-Analysis", 22nd European Photovoltaic Solar Energy Conference, Milano (Italy), 3-7 September 2007.

[5] A. Volkanovski, M. Čepin and B. Mavko, "Optimization of reactive power compensation in distribution networks", Electrotechnical Review 76 (1-2), 2009, pp. 57-62.

[6] D. Thukaram, H. M. Wijekoon Banda, and J. Jerome, “A robust three phase power flow algorithm for radial distribution systems," Electr. Power Syst. Res., vol. 50, no. 3, pp. 227-236, Jun. 1999.

[7] C. S. Cheng and D. Shirmohammadi, "A three-phase power flow method for real-time distribution system analysis," IEEE Trans. Power Syst., vol. 10, no. 2, pp. 671-679, 1995.

[8] P. Aravindhababu, S. Ganapathy, and K. R. Nayar, "A novel technique for the analysis of radial distribution systems," Int. J. Electr. Power Energy Syst., vol. 23, no. 3, pp. 167-171, Mar. 2001. 